\title{
Nothing to be written here
}

\author{
Wendy Oberlander
}

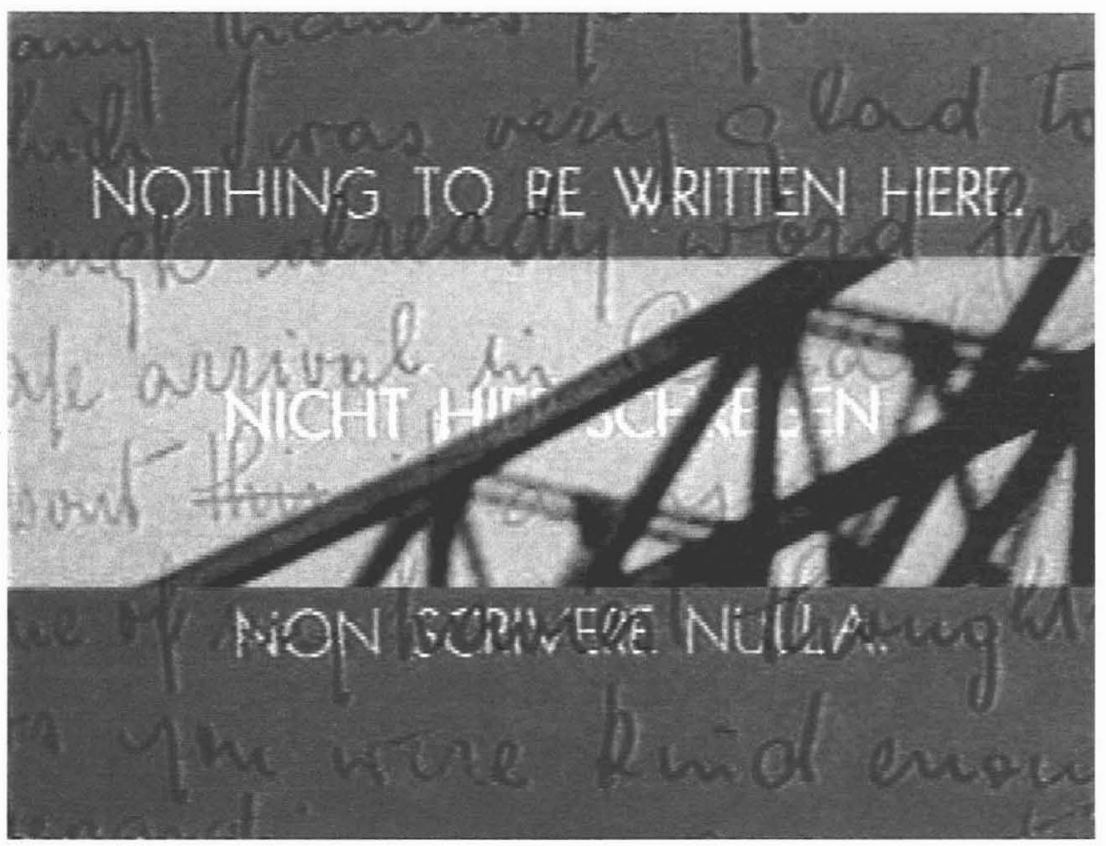

Nothing to be written here explores one short chapter in the Jewish Diaspora of the 20th century. This is not exclusively a Jewish story, but common for those unable to name a home of their own. The video traces the internment of Austrian and German refugees in eastern Canada, from 1940 to 1943. This is the story of my father's arrival in Canada, and the unravelling of my inheritance.

In both Jewish religion and culture, the Book occupies a central position. On the page is inscribed the unspeakable - the name of God, questions without answers, an eternal exile. It reappears - as image and symbol - throughout the video providing a space in which to break a silence, and on which to write my story.

written, directed and produced by Wendy Oberlander edited by Jennifer Abbott camera by Kevin Matthews, Bo Myers and Wendy Oberlander (C) 1996 

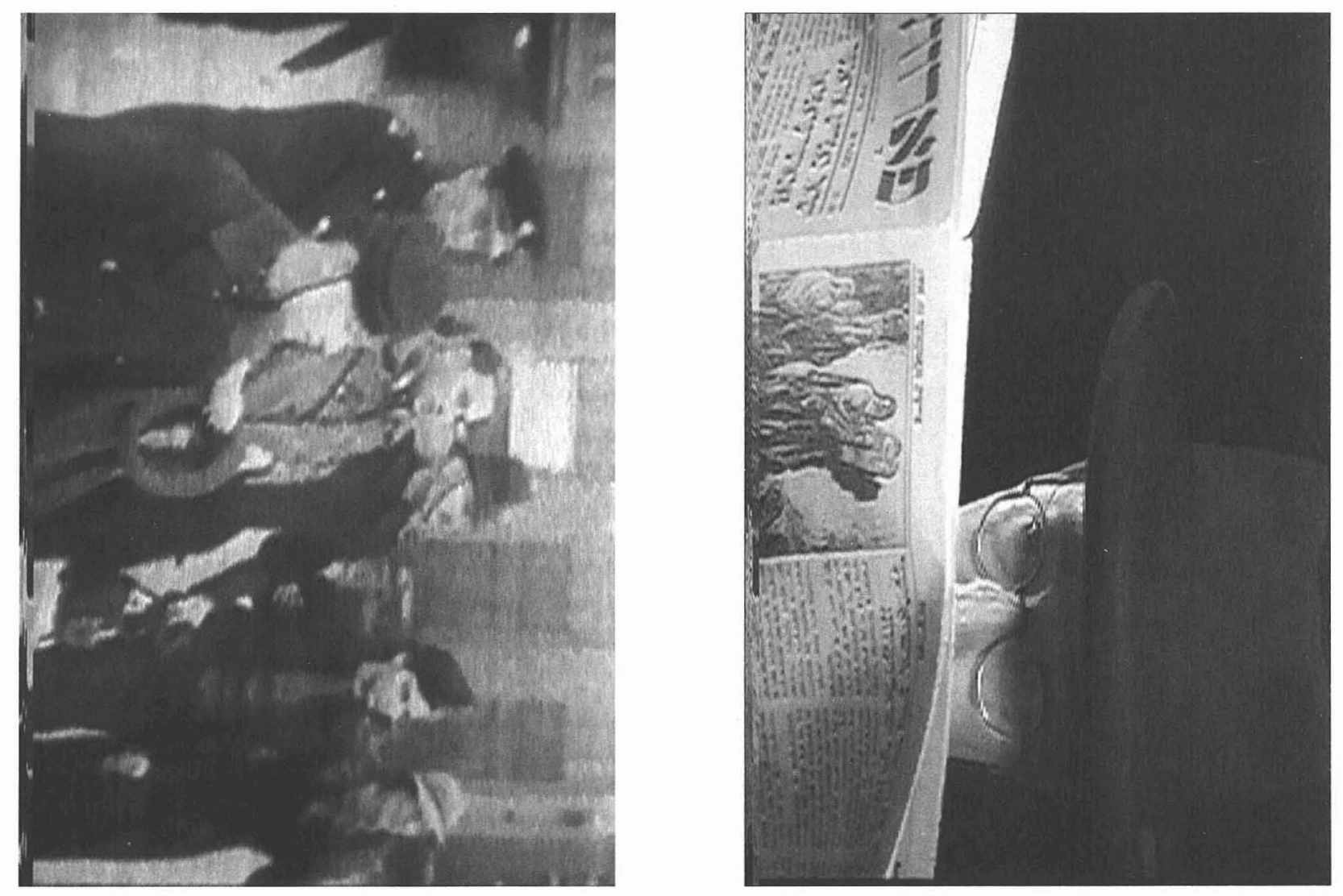